\title{
Dampak Pembangunan Terhadap Hutan Dan Lingkungan Hidup (Studi Kasus Di Kabupaten Polewali Mandar)
}

\author{
Sukaji Sarbi a* \\ ${ }^{a}$ Fakultas Keguruan dan Ilmu Pendidikan (FKIP), Universitas Al Asyariah Mandar (Unasman), Polewali Mandar \\ *Email: sukadjisarbi50@gmail.com \\ Diterima (received) 8 Oktober 2017; disetujui (accepted) 1 Februari 2018; tersedia secara online (available online) 1 Februari 2018
}

\begin{abstract}
Polewali Mandar has a wealth of tropical forests,to the extent of reaching 72.814 ha. As a forest ecosystem, it plays a very important role for human development and health.Therefore, a healthy forest is needed that can support human life.Human growth and development, has provided various negative impacts on forest ecosystems.Forest management that has been applied has not been able to maintain the optimal function of forests, the more damaged forests.Many economic interests dominate the implementation of forest management.In order to maintain and restore forest functions optimally from various threats that increasingly necessary reorientation to change the practices of forest resource management and the environment wisely, so that the crisis destruction of forests and the environment can be controlled.To the community and various parties related to the management of forest resources and the environment needed awareness to embody the moral and ethics of the environment.
\end{abstract}

Keywords: saving forests and the environment.

\begin{abstract}
Abstrak
Kabupaten Polewali Mandar memiliki kekayaan hutan tropis, dengan luasnya mencapai 72.814 ha. Sebagai ekosistem hutan mempunyai peran yang sangat penting bagi pembangunan dan kesehatan manusia. Oleh karena itu diperlukan hutan yang sehat yang mampu mendukung kehidupan manusia. Pertumbuhan manusia dan pembangunan, telah memberikan berbagai dampak negatif terhadap ekosistem hutan. Manajemen kehutanan yang selama ini diterapkan ternyata belum mampu untuk mempertahankan fungsi hutan secara optimal, hutan semakin rusak. Kepentingan ekonomi banyak mendominasi implementasi pengelolaan hutan. Dalam rangka mempertahankan dan mengembalikan fungsi hutan secara optimal dari berbagai ancaman yang semakin meningkat diperlukan reorientasi untuk mengubah praktek-praktek pengelolaan sumberdaya hutan dan lingkungan hidup secara bijaksana, sehingga krisis kerusakan hutan dan lingkungan hidup dapat dikendalikan. Kepada masyarakat dan berbagai pihak yang terkait dengan pengelolaan sumberdaya hutan dan lingkungan hidup diperlukan kesadaran untuk mengemplimentasikan moral dan etika lingkungan.
\end{abstract}

Kata Kunci: Penyelamatan hutan dan lingkungan hidup.

\section{Pendahuluan}

Sebagaimana diketahui bahwa hutan bukan hanya sekumpulan pohon, tetapi merupakan suatu masyarakat tumbuhan yang kompleks, yang terdiri selain dari pohon, juga terdapat semak tumbuhan bawah, jasat renik tanah, dan fauna lainnya. Mereka menjadi satu kesatuan yang satu sama lainnya terikat dalam hubungan ketergantungan. Untuk dapat dikategorikan sebagai hutan, sekelompok pohon-pohon harus memiliki tajuk-tajuk yang cukup rapat, sehingga merangsang pemangkasan secara alamiah, dengan cara menaungi ranting dan dahan dibagian bawah dan menghasilkan tumpukan bahan organik atau serasah yang sudah terurai maupun yang belum terurai di atas tanah mineral. Indriyanto. 2006

doi: https://doi.org/10.24843/blje.2018.v18.i01.p02

(C) 2018 by the authors; Content from this work may be used under the terms of the Creative Commons Attribution 3.0 licence. Any further distribution of this work must maintain attribution to the author(s) and the title of the work, journal citation and DOI. Published under licence by Udayana University, Indonesia. 
mengemukkan bahwa dalam ekosistem hutan juga terdapat unsur-unsur lain yang berasosiasi antara lain tumbuhan yang kecil dan berbagai bentuk kehidupan fauna.

Dalam rangka pengembangan kemampuan pengelolaan hutan dan linngkungan hidup juga adanya berbagai kerusakan hutan dan lingkungan yang saat ini dirasakan semakin meningkat, karena laju degredasi sumberdaya hutan dan lingkungan jauh lebih tinggi jika dibandingkan dengan laju upaya kita sampai dengan saat ini untuk melakukan perlindungan dan pelestarian alam.

Berbagai kerusakan sumberdaya alam yang paling menonjol adalah kerusakan hutan dan lingkungan hidup di Kabupaten Polewali Mandar cenderung terus meningkat, dampak negatifnya pun secara luas terhadap kualitas lingkungan semakin dirasakan bersama. Hal ini sangat terkait dengan semakin meningkatnya jumlah manusia dan pembangunan.

Sukaji Sarbi. 2013. 25 mengemukakan bahwa adanya peningkatan laju pertubuhan penduduk 1,44 persen (BPS Kabupaten Polewali Mandar, 2016), yang diikuti pula dengan laju peningkatan konsumsi, maka ekplotasi terhadap berbagai sumber alam termasuk hutan pun terus meningkat, sehingga saat ini kita semakin sulit untuk membendung kerusakan hutan dan lingkungan hidup. Dilain pihak, terutama karena kemampuan kita untuk menahan laju kerusakan tersebut sangat rendah, jika dibandingkan dengan kekuatan-kekuatan perusak. Berbagai peraturan perundangan pun sulit ditegakkan bagi berbagai pelanggar atau perusak hutan dan lingkungan hidup.

Kita dapat pahami bahwa secara akademis, kita juga telah berhasil mengenali berbagai penyebabnya. Namun, dalam kenyataanya tetap sulit untuk mengemplementasikan pencegahan ataupun penanggulangan kerusakan hutan dan lingkungan tersebut. Hasanu Simon. 2010.12. mengemukakan bahwa proses tersebut terus berlanjut yaitu kecepatan laju pertumbuhan pohon muda semakin tidak dapat mengimbangi laju penebangan, sehingga umur hutan sekunder yang ditebang sudah dibawah daur tehnik . Karena memang akar pernasalahannya sangat rumit, menyangkut berbagai aspek sosial, ekonomi, budaya maupun politik dari berbagai lapisan masyarakat pigir kawasan hutan yang beranekaragam. Salah satu yang banyak disoroti di daerah ini adalah faktor kemiskinan, persoalan perut, hal ini seharusnya segera dipecahkan secara komprehensip, sehingga tepat jika agenda pengelolaan hutan dan lingkungan hidup dikaitkan dengan pengentasan kemiskinan.

Disamping itu, salah satu sebab utamanya adalah sulitnya merobah moral pelaku ekonomi dan lajunya pembangunan didaerah ini. Sering kali mereka hanya berorientasi kepada keuntungan ekonomi jangka pendek, yang sangat bertentangan dengan tujuan keuntungan ekologi lingkungan jangka panjang, terutama bagi perlindungan hutan dan lingkungannya. Hutan-hutan alam yang memiliki keragaman hayati yang tinggi diubah menjadi hutan sejenis ataupun tanaman perkebunan. Kegiatan eksplotasi hutan dilakukan tanpa perhitungan kemampuannya, bahkan terjadinya penebangan pohon yang tidak tebang pilih, sehingga sulit untuk memperoleh hutan lestari.

Tujuan penelitian agar hutan tetap terjaga : (1). karena hutan sebagai suatu ekosistem tidak hanya menyimpan sumberdaya alam berupa kayu dan masih banyak potensi non kayu yang dapat diambil manfaatnya oleh masyarakat melalui budidaya tanaman pertanian pada lahan hutan, (2). juga sangat berperan dalam berbagai hal seperti penyedia sumber air, penghasil oksigen dan (3). tempat hidup dari berbagai flora dan fauna, dan juga menjadi peran penyeimbang lingkungan, serta lebih luas lagi mencegah timbulnya pemanasan global.

\section{Metode Penelitian}

\subsection{Keadaan Umum Kabupaten Polewali Mandar}

Daerah ini, sebelum diberi nama Polewali Mandar, bernama Kabupaten Polewali Mamasa yang secara administratif berada dalam Wilayah Provinsi Sulawesi Selatan. Setelah daerah ini dimekarkan dan dengan berdirinya Kabupaten Mamasa sebagai kabupaten tersendiri, maka nama Polewali Mamasa pun diganti menjadi Polewali Mandar dengan luas wilayah 2.022,30 $\mathrm{Km}^{2}$ (Permendagri No.56 Tahun 2015). Nama kabupaten ini resmi digunakan dalam proses administrasi pemerintahan sejak tanggal 1 Januari 2006 setelah ditetapkan dalam bentuk Peraturan Pemerintah Nomor 74 Tahun 2005 tanggal 27 Desember 2005 tentang perubahan nama Kabupaten Polewali Mamasa menjadi Kabupaten Polewali Mandar. 
Daerah ini jika dikaji dari posisi geografisnya, maka berdasarkan data BPS Kabupaten Polewali Mandar (2016), dengan jumlah penduduk 455.572 jiwa dengan ibukotanya Polewali terletak antara 20.40.' - 3032' LS dan 1180. 40' - 1190. 32' BT mempunyai luas Wilayah 2. 022,30 km2 terdiri atas 16 Kecamatan, 26 Kelurahan dan 132 Desa dengan batas-batas wilayah sebagai berikut: (a). Sebelah Selatan berbatasan dengan laut Selat Makassar, (b). Sebelah Utara berbatasan dengan Kabupaten Mamasa, (c). Sebelah Timur berbatasan dengan Kabupaten Pinrang dan (d) Sebelah Barat berbatasan dengan Kabupaten Majene.

\subsection{Data dan Potensi Hutan}

Mengenai luas hutan Kabupaten Polewali Mandar yang ada saat ini. Berdasarkan data DLHK Kabupaten Polewali Mandar (2016), menunjukkan bahwa luas kawasan hutan Kabupaten Polewali Mandar seluas 72.814 ha. Sesuai dengan fungsinya, kawasan hutan di daerah ini dibagi; (a) Hutan lindung 55.375 ha. Pemerintah Daerah telah menetapkan hutan lindung diperuntukan bagi pengendalian banjir dan erosi. (b) Hutan produksi 16,539 ha. Hutan produksi dikelola untuk produksi hasil hasil hutan, maupun non kayu sedangkan (c) Hutan konservasi 900 ha (cagar alam, taman wisata, suaka margasatwa) ditetapkan bagi kepentingan perlindungan dan pelestarian keanekaragaman hayati, rekreasi dan pariwisata serta ilmu pengetahuan.

Potensi hutan sangat berbeda dari satu daerah dengan daerah lainnya, hal ini sangat terkait dengan zona-zona biogeografinya. Khusus untuk zona Kabupaten Polewali Mandar yang kaya hasil hutan misalnya Kayu Uru, Rango, Bakan Lea, Bakan Kaki, Kanusuan, Binuang, Langgogo, Tipulu, Kemiri, Sukun, Sattung, Betti atau Laban, Kenanga dan Rotan. Produksi hutan, khususnya kaju dan rotan merupakan sumber dari pendapatan dan perdagangan masyarakat didaerah ini. Sebagian besar menjadi bahan industri lokal dari masyarakat sekitar kawasan hutan yang dengan ketergantungannya dari hutan. Dilihat dari sudut ekonomi sub sektor industi kehutanan secara umum diperoleh kayu gergajian sebanyak 2.025.238 $\mathrm{m} 3$ dan dari hutan sekunder diperoleh dalam bentuk rotan sebanyak $1.375 \mathrm{~m} 3$. (DLHK Kabupaten Polewali Mandar, 2016).

\section{Pembahasan}

Kita pahami bersama secara akademik dengan berbagai diskusi, seminar, bahkan workshop tentang konservasi hutan dan lingkungan hidup telah banyak dilaksanakan selama 10 tahun terakhir. Ini menandakan semakin meningkatnya kepedulian kita terhadap pentingnya hutan dan lingkungan hidup, bahkan kitapun sudah mengenali dengan baik berbagai akar permasalahan semakin merosotnya kondisi hutan dan lingkungan hidup. Berdasarkan pemantauan lapangan kenyataan yang terjadi dengan adanya kerusakan-kerusakan hutan dan lingkungan hidup di Kabupaten Polewali Mandar ini merupakan akibat dari aktivitas manusia yang tidak memperhatikan aspek ekologi seperti:

a. Alih pungsi hutan menjadi ladang kelapa sawit, kakao dan ladang jahe.

b. Peladang berpindah-pindah.

c. Pengelolaan hutan yang kurang bijaksana.

d. Penebangan pohon untuk keperluan bangunan kantor, rumah, mobiler, papan.untuk cor pondasi.

e. Penebagangan pohon untuk diperjual belikan pada pedagang kayu.

f. Penebangan pohon untuk kayu bakar rumah tangga, kayu bakar untuk membakar batu merah.

g. Penebangan pohon / kayu untuk membakar kerajinan home industry yang terbuat dari tanah.

Keputusan mereka ini mempunyai dampak yang sangat luas terhadap kerusakan hutan dan lingkungan hidup. Saat ini masih terdapat suatu polemik antara konsep pembangunan secara umum dengan upaya pengembangan sumberdaya hutan dan lingkungan, dimana pada prinsipnya tidak saling tolak belakang. Berdasarkan data DLHK Kabupaten Polewali Mandar (2016), mengenai luas lahan kritis dalam kawasan, akibatnya kegiatan manusia berdampak buruk terhadap hutan dan lingkungannya sebagaimana yang terlihat pada Tabel. 1 . 
S Sarbi; Dampak Pembangunan Terhadap Hutan Dan Lingkungan Hidup (Studi Kasus Di.....

Tabel 1. Luas Lahan Kritis Dalam Kawasan Hutan

\begin{tabular}{cccc}
\hline No. & Area Kawasan & Keadaan & Luas (hektar) \\
\hline 1. & Hutan & Potensial Krtitis & 32.530 \\
2. & Hatan & Agak Kritis & 13.608 \\
3. & Hutan & Kritis & 42,886 \\
4. & Hutan & Sangat Kritis & 28,56 \\
\hline \multicolumn{2}{l}{ Sumber: DLHK Kabupaten Polewali Mandar (2016) }
\end{tabular}

Sedangkan mengenai luas lahan kritis di luar kawasan, akibatnya kegiatan manusia berdampak buruk terhadap hutan dan lingkungannya hal ini sebagaimana yang terlihat pada Tabel. 2 .

Tabel 2. Luas Lahan Kritis di luar Kawasan Hutan

\begin{tabular}{cccc}
\hline No & Area Kawasan & Keadaan & Luas (hektar) \\
\hline 1. & Hutan & Tidak Krtitis & 21.161 .53 \\
2. & Hatan & Potensial Kritis & 22.783 .07 \\
3. & Hutan & Agak Kritis & $25,366.35$ \\
4. & Hutan & Kritis & 45.408 .62 \\
5. & Hutan & Sangat kritis & 28,56 \\
\hline
\end{tabular}

Sumber: DLHK Kabupaten Polewali Mandar (2016)

Berdasarkan data pada BPBD Kabupaten Polewali Mandar (2016), bencana alam pada 2 (dua) tahun terakhir hal ini sebagaimana yang terlihat pada Tabel 3

Tabel 3. Lokasi dan Jenis Kerusakan Benca Alam

\begin{tabular}{ccccccc}
\hline \multirow{2}{*}{ No. } & Tanggal & \multicolumn{2}{c}{ Lokasi } & & Jenis & \multicolumn{2}{c}{$\begin{array}{c}\text { Jenis Kerusakan \& Keadaan } \\
\text { Rumah }\end{array}$} \\
& & Dencana & Kecamatan & Alam & Ringan & Berat \\
\hline 1. & $12-2-2016$ & Kanusuang & Luyo & Longsor & 2 & 5 \\
2. & $21-2-2016$ & Anreapi & Anreapi & Longsor & 5 & 4 \\
3. & $17-3-2016$ & Papandangan & Anreapi & Longsor & 7 & 6 \\
4. & $30-3-2016$ & Kurra & Tapango & Longsor & 3 & 2 \\
5 & $24-9-2016$ & Anreapi & Anreapi & Longsor & - & 2 Rumbel SD \\
\hline
\end{tabular}

Sumber: BPBD (2016).

Jika kerusakan hutan ini terus berlangsung, maka tidak menutup kemungkinan terjadi di daerah ini krisis lingkungan yang berkepanjangan, kemerosotan produktivitas lahan pangan yang luar biasa dan menurunya ketersedian air dari hutan. Kepala Desa Papandangan bekerja sama dengan Kodim 1402 Kabupaten Polewali Mandar dan Mahasiswa Pencinta Lingkungan (Mapala) Universtas Al Asyariah Mandar, telah melakukan penanaman pohon jati putih sebanyak 1.500 .000 pohon di lokasi area longsor dan area yang rawan lonsor di Desa Papandangan.

Pepohonan dalam ekosistem hutan mempunyai peranan penting tidak hanya dalam siklus air, akan tetapi juga berperan dalam pengawetan tanah dan dalam siklus air pohon merupakan pemindahan air hujan ke tanah melalui proses penahan sementara air hujan oleh tajuk pohon, sehingga tidak langsung jatuh ketanah melainkan menimpah dedaunan. Penahanan air hujan oleh tajuk pohon akan mengurangi resiko gangguan terhadap pori-pori tanah, sehingga aliran permukaan dapat terkendalikan.

Dalam rangka melindungi dan melestarikan hutan dan lingkungan hidup, maka Dinas Kehutanan dan Lingkungan Hidup Kabupaten Polewali Mandar tidak lagi memberikan izin baru kepada pengusahapengusaha kakao, kelapa sawit atau pengusaha lainnya yang mau investasi membuka usaha yang berkaitan dengan kehutanan. Bagi lahan-lahan yang mengalami kerusakan ataupun lahan kritis dilakukan rehabilitasi dan reboisasi hutan. Rehabilitasi hutan dan lingkungan hidup dimaksudkan untuk memulihkan, mempertahankan, dan meningkatkan fungsi hutan dan lingkungan hidup, sehingga daya dukung, 
produksivitas, dan peranannya dalam mendukung sisten penyangga kehidupan tetap terjaga. Mengenai rehabilitasi hutan dan lingkungan hidup diselenggarakan melalui kegiatan penghijauan, pemeliharaan, pengayaan tanaman, atau penerapan teknik konservasi tanah secara vegetatif dan pada lahan kritis dan lahan tidak produktif.

Dalam rangka pengelolaan sumberdaya hutan dan lingkungan hidup secara benar sangat terkait dengan kemampuan berbagai institusi di Daerah Kabupaten Polewali Mandar seperti kebijakan (aturan termasuk norma dan etika) organisasi dan tentunya sebagai inti pokoknya adalah sumberdaya manusia yang mampu menjalankan semua organisasi, aturan, norma ataupun penegakan hukum yang berlaku dalam konteks pembangunan yang berwawasan lingkungan. Komponen-komponen institusi daerah sangat perlu untuk terus ditingkatkan kemampuannya, sehingga dapat mempertautkan kepentingan generasi mendatang dengan kepentingan generasi sekarang dalam melaksanakan pembangunan. Tersimpulkan disini adanya keharusan mewariskan sumber-sumber alam inclusit sumberdaya hutan dan lingkungan secara lestari kepada generasi mendatang agar dapat dikelola secara sambung sinambung antar generasi ke generasi sepanjang zaman.

\section{Kesimpulan}

a. Kabupaten Polewali Mandar memiliki sumberdaya alam hutan topis yang sangat penting peranannya, sehingga harus tetap terjaga dalam pertumbuhan pembangunan dan fungsi ekologis secara lokal, nasional maupun secara global.

b. Seiring dengan laju pertubuhan penduduk 1,44 persen, maka hutan dan lingkungan hidup mengalami kerusakan, hingga akhir tahun 2017 ini luas hutan yang sangat kritis mencapai 28,56 ha, sehingga penghijauannya perlu dilanjutkan..

c. Berbagai program rehabilitasi dan pengelolan hutan lestari dan lingkungan hidup yang dilakukan oleh Pemerintah Daerah Kabuapten Polewali Mandar belum memperoleh hasil secara signifikan dalam memperbaiki dan mencegah kerusakan hutan dan lingkungan hidup.

\section{Saran}

a. Diharapkan pada Pemerintah Daerah Kabupaten Polewali Mandar mensosialisasikan kembali Peraturan Daerah (Perda) tentang larangan penebangan pohon yang dilakukan masyarakat sekitar kawasan hutan, agar pohon yang masih ada tetap terjaga.

b. Melanjutkan kembali penghijauan yang telah dikerjakan oleh TNI AD yang dipimpin Dandim 1402 Kabupaten Polewali Mandar bekerjsama dengan Mahasiswa Pencinta Lingkungan (Mapala) Universitas Asyariah Mandar.

Menggiatkan kembali Polisi Kehutanan (Polhut) yang berada dalam naungan Dinas Kehutanan dan Lingkungan Hidup Kabupaten Polewali Mandar.

\section{Daftar Pustaka}

BPS Kabupaten Polewali Mandar. (2016). Polewali Mandar Dalam Angka Tahun 2016. Polewali Mandar, Indonesia: Badan Pusat Statistik Kabupaten Polewali Mandar.

BPBD Kabupaten Polewali mandar. (2016). Statistik Bencana Polewali Mandar 2016. Polewali Mandar, Indonesia: Badan Penanggulangan Bencana Daerah Kabupaten Polewali Mandar.

Republik Indonesia. (1999). Undang-Undang Republik Indonesia Nomor. 41 Tahun 1999 Tentang Kehutanan. Lembaran Negara Republik Indonesia Tahun 1999 Nomor 167. Jakarta, Indonesia: Sekretariat Negara Republik Indonesia.

Republik Indonesia. (2009). Undang-Undang Republik Indonesia Nomor. 32 Tahun 2009 Tentang Perlindungan dan Pengelolaan Lingkungan Hidup. Lembaran Negara Republik Indonesia Tahun 2009 Nomor 140. Jakarta, Indonesia: Sekretariat Negara Republik Indonesia. 
DLHK Kabupaten Polewali Mandar. (2016) Kajian Lingkungan Hidup Strategis (KLHS) Rencana Pembangunan Jangka Menengah Daerah (RPJMD) Kabupaten Polewali Mandar. Polewali Mandar, Indonesia: Dinas Lingkungan Hidup dan Kehutanan Kabupaten Polewali Mandar.

Indriyanto. (2006). Ekologi Hutan. Jakarta, Indonesia: Penerbit Bumi Aksara. .

Sarbi, S. (2006). Strategi Pengembangan Kapasitas Pengelolaan Lingkungan Hidup di Era Otonomi Daerah Kabupaten Polmas Sulawesi Barat. Jurnal Bumi Lestari, 6(2), 100-105.

Sarbi, S. (2012). Kontribusi Perguruan Tinggi Terhadap Lingkungan Hidup. Makassar, Indonesia: Penerbit Kretakuta.

Sarbi, S. (2013). Lingkungan Hidup. Makassar, Indonesia: Penerbit Kretakuta.

Sarbi, S. (2017). Sistem Sumberdaya Alam dan Lingkungan Hidup. Makassar, Indonesia: Penerbit UMI Press

Simon, H. (2010). Perencanaan pembangunan sumber daya hutan. Yogyakarta, Indonesia: Penerbit Pustaka Pelajar. 